\title{
THE DECEMBER MEETING AT DES MOINES
}

The two hundred seventy-sixth regular meeting of the Society was held at Des Moines on Monday and Tuesday, December 30-31, 1929, in conjunction with the meetings of the American Association for the Advancement of Science and the Mathematical Association of America. The meetings and dinner were held in the Hotel Fort Des Moines.

On Monday morning, after a general session of the Society, two sessions, one on algebra and number theory and one on applied mathematics, were held.

On Monday afternoon the Society met in a joint session with Section A of the American Association for the Advancement of Science. At this meeting Professor R. C. Archibald gave his retiring address as Vice-President of the American Association for the Advancement of Science and Chairman of Section A on Mathematics before the Greeks. This was followed by an address given on invitation of the Program Committee by Professor O. D. Kellogg on An unsolved problem in potential theory. It is not expected that the address of Professor Kellogg will be published. An abstract which furnishes references where most of the material of his address may be found appears on p. 201 as Abstract No. 36-3-133.

On Tuesday morning the Society met in three sections. One section met with Section K of the American Association for the Advancement of Science for papers on mathematical statistics; another was devoted to analysis; and the third, to geometry.

Tuesday afternoon the Society met jointly with the Mathematical Association of America and listened to an address, given on the invitation of the Program Committees of both organizations, by Professor L. L. Dines on Linear inequalities and some related properties of functions. This address will appear in an early issue of this Bulletin.

Later in the same afternoon Professor Irving Fisher delivered the seventh Josiah Willard Gibbs lecture under the joint auspices of the Society and the American Association for the Advancement of Science. His address was on The applications 
of mathematics to the social sciences. Professor Fisher spoke of the work and personality of Gibbs and then traced the growth of the use of mathematics in the social sciences with especial emphasis on its use in pure economic theory. This address will appear in an early issue of this Bulletin.

On Tuesday evening a joint dinner of the mathematical organizations was attended by 129 persons. The toastmaster, Professor W. H. Bussey, called upon Professor H. L. Rietz who welcomed the mathematicians to Iowa, Professor J. W. Young, President of the Mathematical Association of America, Professor Jewell Hughes, and President E. R. Hedrick. Professor Dunham Jackson moved a resolution of thanks to those who had helped entertain the mathematicians and arranged for their meetings. This was passed by a rising vote.

The Gibbs lecture was attended by over four hundred persons. The other meetings of the Society were attended by about 150 persons including the following 101 members of the Society:

N. L. Anderson, R. C. Archibald, Ashton, Atchison, R. W. Babcock, R. P. Baker, Blue, Brenke, Bussey, Cairns, H. C. Carter, E. H. Carus, Chittenden, Coffin, J. T. Colpitts, Comstock, Curtiss, Daniells, Daugherty, Dines, Doole, C. W. Emmons, H. P. Evans, Everett, Finkel, Irving Fisher, Gaba, Gouwens, Harper, W. L. Hart, Hassler, Haynes, E. R. Hedrick, Herr, Hinrichsen, Holl, Hosford, Hotelling, J. C. Hughes, Hunter, Byron Ingold, Louis Ingold, Ingraham, Dunham Jackson, Kearney, O. D. Kellogg, Kennelly, Kovarik, E. P. Lane, Langer, Lytle, McClenon, Dorothy McCoy, McGaw, J. V. McKelvey, M. M. McKelvey, MacMillan, Michal, U. G. Mitchell, C. N. Moore, Muehlman, Neff, Pattengill, Pehrson, Pepper, Pettit, Raynor, J. F. Reilly, Remick, H. L. Rietz, Risley, B. D. Roberts, G. E. Robinson, Roever, Roos, Sellew, Sherer, Shewhart, Shirk, Slaught, Slotnick, E. R. Smith, G. W. Smith, H. F. Smith, Snedecor, Eugene Stephens, Stouffer, Tappan, J. S. Turner, Wall, L. E. Ward, Warren Weaver, M. J. Weiss, J. J. Wheeler, K. P. Williams, F. E. Wood, L. P. Woods, Roscoe Woods, Wyant, J. M. Young, J. W. Young.

At the general session on Monday morning President Hedrick and Professor Kellogg presided; in the section on algebra and theory of numbers, Professor Curtiss; and in the section on applied mathematics, Professor C. N. Moore. Monday afternoon at the joint session with Section A Professor Jackson presided. Tuesday morning the presiding officers were Professor Rietz in the joint session with Section K, President Hedrick and Professor Brenke in the section on analysis, and Vice- 
President Lane in the section on geometry. At the joint meeting with the Mathematical Association of America President Young of the Association presided, while President Hedrick presided at the Gibbs lecture.

The titles and cross-references to the abstracts* of the papers read at the regular sessions appear below: papers 1-6 in the general session Monday morning, papers $7-10$ in the section on algebra and number theory Monday morning, papers 11-13 in the section on applied mathematics Monday morning, papers 14-19 in the joint session with Section $K$ on Tuesday morning, papers $20-28$ and 36 in the section on analysis Tuesday morning, and papers 29-35 in the section on geometry Tuesday morning. Papers 5, 6, 7, 10, 17, $25,26,27$, and 28 were read by title, as is indicated by the letter $t$ after the abstract number. Mr. E. W. Anderson was introduced by Professor D. L. Holl; Professor A. H. Meyer, by Professor H. L. Rietz; and Professor C. T. Bumer, by Professor Michal.

1. Integral surfaces of pairs of partial differential equations of the third order, by Professor E. P. Lane. (Abstract No. 36-3-134.)

2. The analog of the projective connection in function space, by Professor A. D. Michal. (Abstract No. 36-3-135.)

3. On the nature of the composite numbers in an arithmetic progression, by Professor C. N. Moore. (Abstract No. 36-3-136.)

4. On groups defined by $A^{q}=1, B^{-1} A B=A^{x}, B^{Q}=A^{e}$, by Dr. Marie J. Weiss, (National Research Fellow.) (Abstract No. 36-3-137.)

5. On subsets of locally connected continua as Borel sets, by Professor W. L. Ayres. (Abstract No. 36-3-138-t.)

6. Generalized Green's matrices for compatible systems of differential equations, by Dr. W. T. Reid, (National Research Fellow.) (Abstract No. 36-3-139-t.)

7. Inverse correspondences in automorphisms of abelian groups, by Professor G. A. Miller. (Abstract No. 36-3-140-t.)

8. The ideals in the algebra of generalized quaternions over the field of rational numbers, by Dr. E. Kathryn Wyant. (Abstract No. 36-3-141.)

* The cross-reference gives the number of the volume, the number of the issue in which the abstract is printed, and the number of the abstract itself. 
9. Some identities connected with Fermat's last theorem, by Professor J. S. Turner. (Abstract No. 36-3-142.)

10. Matrices whose characteristic equations are cyclic, by Proffessor T. A. Pierce. (Abstract No. 36-3-143-t.)

11. On the problem of $n$ bodies, by Dr. J. J. L. Hinrichsen. (Abstract No. 36-3-144.)

12. Limits of approximate solutions of the torsion problem, by Mr. E. W. Anderson. (Abstract No. 36-3-145.)

13. A two-dimensional boundary-value problem for the transmission of alternating currents through a semi-infinite heterogeneous conducting medium, by Professor H. P. Evans. (Abstract No. 36-3-146.)

14. On certain inequalities with applications in actuarial theory, by Professor H. A. Meyer. (Abstract No. 36-3-147.)

15. The standard error of a forecast from a curve, by Professor Henry Schultz. (Abstract No. 36-3-148.)

16. On certain properties of frequency distributions whose variates are obtained by linear fractional transformation of the variates of a given distribution, by Professor H. L. Rietz. (Abstract No. 36-3-149.)

17. On the probability associated with a given range, by Professor P. R. Rider. (Abstract No. 36-3-150-t.)

18. The consistency and ultimate distribution of optimum statistics, by Professor Harold Hotelling. (Abstract No. 363-151.)

19. An analysis of frequency distributions, by Professor G. R. Davies. (Abstract No. 36-3-152.)

20. On the Dirichlet-Neumann problem, by Professor G. E. Raynor. (Abstract No. 36-3-153.)

21. On the Pade approximants associated with a positive definite power series, by Dr. H. S. Wall. (Second communication.) (Abstract No. 36-3-154.)

22. Some properties of $\nabla^{4} \psi=0$, when expressed in curvilinear coordinates, by Professor D. L. Holl. (Abstract No. 36-3-155.)

23. Relation of Maschke's symbolic method to the tensor theory, by Mr. H. C. Carter. (Abstract No. 36-3-156.)

24. The differential geometry of a continuous infinitude of contravariant functional vectors, by Professor A. D. Michal. (Abstract No. 36-3-157.) 
25. On dynamical systems with $n$ degrees of freedom subject to hysteresis effects of the Fredholm type, by Professors A. D. Michal and C. T. Bumer. (Abstract No. 36-3-158-t.)

26. On some remarkable theorems on geodesic coordinates of order $r$ in n-dimensional differential geometries, by Professor A D. Michal. (Abstract No. 36-3-159-t.)

27. Concerning algebro-functional groups of transformations and the theory of projective functional tensors, by Professor A. D. Michal. (Abstract No. 36-3-160-t.)

28. Dynamical systems with infinite degrees of freedom and their integral invariants, by Professor A. D. Michal. (Abstract No. 36-3-161-t.)

29. A note on a projective invariant of a conjugate net, by Professor M. M. Slotnick. (Abstract No. 36-3-162.)

30. The projective equivalence of two nets of conics, by Professor F. E. Wood. (Abstract No. 36-3-163.)

31. A condition for the concurrence of three common chords of three conics, taken in pairs, by Professor J. S. Turner. (Abstract No. 36-3-164.)

32. Invariant normals to a space $S_{n}$ contained in a function space, by Dr. Nola L. Anderson and Professor Louis Ingold. (Abstract No. 36-3-165.)

33. On the structure of sets of points of classes one, two, and three, by Professor A. H. Blue. (Abstract No. 36-3-166.)

34. The complete existential theory of eight fundamental properties of topological spaces, by Professor Dorothy McCoy. (Abstract No. 36-3-167.)

35. A set of axioms in terms of points, ordinary and ideal, by Professor M. G. Gaba. (Abstract No. 36-3-168.)

36. On the zeros of certain rational functions, by Dr. Morris Marden, (National Research Fellow.) (Abstract No. 36-3-169.)

M. H. INGRAHAM, Associate Secretary 